\title{
Replacement of Diesel Generator Sets in Isolated Communities with More Efficient Biomass Combustion Process
}

\author{
Victor Bicalho Civinelli de Almeida and Marco Aurélio da Cunha Alves \\ Production and Mechanical Engineering Department, Federal University of Juiz de Fora, Juiz de Fora 36025-320, Brazil
}

Received: November 29, 2012 / Accepted: February 19, 2013 / Published: December 31, 2013.

\begin{abstract}
Electrical power supply to communities isolated from urban areas is typically complex and expensive. Their geographical situation and the lack of infrastructure and qualified workforce impede the provision of electricity. Many are the sources of energy available, but few are appropriate or sustainable. Combustion of diesel fuel is a good technical solution; however, it is neither economic nor environmentally tenable. This paper presents the advantages of using biomass as an energy source, along with its potential increase in efficiency when steam is generated in specific circumstances of temperature and pressure.
\end{abstract}

Key words: Biomass, direct combustion, electrification, isolated communities, steam engine.

\section{Introduction}

The Brazilian population's access to electricity still presents great geographic contrast [1]. Despite abundant energy in urban centers, the exclusion of isolated communities from the NIS (national interconnected system) is significant, greatly hampering their local development.

Up to now, given the logistical difficulties, the federal government has chosen not to link certain areas lacking electricity to the NIS, and created the BIS (Brazilian isolated systems) [2], aiming at special energy supply to geographic areas with similar infrastructure. In most cases, the immediate solution resides in installing thermal power plants working on fossil fuels, especially diesel with elevated economic and environmental accountability.

It is crucial herein to point out the social, economic and environmental advantages of sustainable use of local biomass, combined with an efficient technology

Corresponding author: Victor Bicalho Civinelli de Almeida, researcher, research field: mechanical engineering. E-mail: victor.bicalho@engenharia.ufjf.br. for generating electricity to isolated communities. This high efficiency will be achieved using a fluid working at high pressure and temperature, as established in previous studies, such as Ref. [3].

\section{Energy in IC (Isolated Communities)}

While the vast majority of urban populations worldwide have guaranteed access to a power grid, a significant part of society is deprived of its benefits. The lack of electricity in the Brazilian countryside is still widespread, evidence of which can be seen in the recent extension of the National Program for Universal Access and Use of Electric Power- "LUZ PARA TODOS”, published officially by Decree No 7520 (July 8, 2011). The postponement of the conclusion of the program reveals that providing electricity for the entire population is a difficult task, which requires not only public initiative, but also the choice of the appropriate technology to be used for generation, providing reliability, low operating cost and efficiency.

It should be remembered that even in those states well provided with electricity there are deficient 
regions, especially in rural areas. Fig. 1 shows the percentage of rural electrical exclusion by federal unit, highlighting the lack of localized generation or efficient distribution of energy [1].

To reduce these numbers, the federal government has built power plants fueled by petroleum-based fuels, especially diesel oil [4]. Their geographical position follows the same spatial location as the BIS [5]. It is clear that the immediate solution adopted by the government to the exclusion of the BIS comes down to the burning of fossil fuels and micro-regional transmission of electricity. It must be emphasized that the supply of fuel for the IC is sometimes extremely laborious and expensive, consuming resources and energy in a complicated multimodal logistics process. It is important to consider whether there would be other energy sources to the region more convenient than the expensive transportation of petroleum derivatives.

\section{Renewable Sources of Energy for Isolated Communities}

Adopting a renewable energy source, with minimal environmental impact, is undoubtedly the most appropriate approach for the IC. In addition to avoiding unwanted emissions, especially carbon dioxide $\left(\mathrm{CO}_{2}\right)$ unbalanced, typical characteristic of burning fossil fuels, the use of a renewable energy infrastructure creates local employment and promotes the socioeconomic development of the IC.

There are several renewable energy sources for the IC, which, however, are dependent on geographic and technological conditions offered regionally. Among the most commonly used, it is possible to mention.

\subsection{Solar Energy}

Used for direct heating and photovoltaic generation. After acquisition, this type of energy has a not too short payback, but minimal environmental impact. It is expensive for the IC, however, when the number of households served exceeds seven [6]. Other difficulties include the large area required for installation of panels and intermittence due to clouds and darkness [7].

\subsection{Hydropower and Hydrokinetic}

The transformation of kinetic or potential energy of water flows into electricity. For small communities, the installation of micro and small hydroelectric plants is discouraged because they require special conditions of waterfalls, and constant maintenance. In addition the use of hydrokinetic turbines require currents with a minimum speed of $1.5 \mathrm{~m} / \mathrm{s}$ and a wide bed [6], conditions not so favorable to the majority of the IC nearby rivers.

\subsection{Wind Power}

Makes use of the movement of the wind to spin turbines connected to generators. Despite being an extremely clean energy source, it is difficult for the IC to acquire the equipment and wind currents of a reasonable magnitude and certain regularity are necessary, rarely found in Brazilian IC. In addition, it does not provide power consistently, depending on the

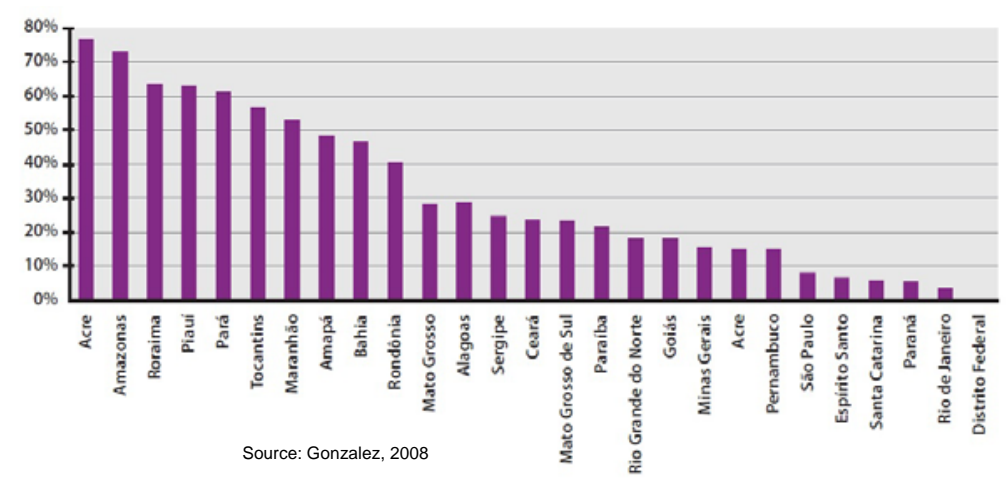

Fig. 1 Index of rural electric exclusion by Brazilian federal state. 
wind system site. Finally, it generates visual pollution and noise (due to the rotors), causing electromagnetic interference that disrupts adjacent communication and data transmission systems [7].

\subsection{Biomass}

For energy purposes, biomass can be defined as "organic matter of vegetable or animal origin that can be converted into thermal or electric energy" [5]. In practice, the potential energy from biomass is the indirect storage of solar radiation through the process of photosynthesis, sequestering $\mathrm{CO}_{2}$ from the atmosphere and incorporating the carbon in the plant structure. The production cost of energy by fuel in Brazil can be seen in Fig. 2 (in which biomass is exemplified by sugar cane bagasse), revealing the economic advantage of biomass against other energy sources such as diesel and fuel oils [5].

Biomass can be classified into five groups [8]: virgin wood, energy crops, agricultural residues, food and industrial waste and by-products. What will be discussed here is particularly the use of the first three sets, since they are the ones available to a greater or lesser degree to communities isolated from urban centers.

The share of biomass in the Brazilian energy matrix represents less than $5 \%$ of the domestic supply of electricity [9] and therefore has great potential for expansion. Compared with world electricity generation [10], described in Fig. 3, the Brazilian supply shows a natural preference for hydropower. There are, however, many groups isolated from urban areas which have no access at all to this hydroelectric potential.

The environmental impact arising from the combustion of biomass becomes almost harmless when combined with proper forest management. The method of less impact would be to burn the collection of waste extraction, thus avoiding losses of highly energetic material [11-13]. For the project presented here, it could be a possibility to use cut firewood, but the feasibility of this practice demands a careful study of sustainability. The reforestation of biomass would cause an immediate reduction of $\mathrm{CO}_{2}$ emissions to values close to zero, with a viable carbon balance.

\section{Biomass to Energy Conversion Technology}

To understand the historical reality lived by isolated communities, particularly those located in the Amazon Region Rivers, the study of the seminal work of Ref. [14] is fundamental. The following analysis was based on this compendium.

Electricity generation in isolated systems is mostly thermal powered by diesel oil. There are two reasons for this: the simplicity of installation, operation and maintenance of diesel generator sets and the government subsidy to the fuel coming from the "fuel consumption account" tax, specially designed for isolated systems. In addition, diesel generator sets can be quickly assembled and have a small installation cost compared to biomass generation ( $\mathrm{R} \$ 650 / \mathrm{kW}$-installed for diesel compared to $\mathrm{R} \$ 1,600 / \mathrm{kW}$-installed for biomass). The time between acquisition and operation varies from 4 to 8 months depending on the power required and can be purchased with specification 7.5 kVA to 1 MVA [15]. These systems do not require many operators, and may even be fully automated for remote control. The maintenance of this technology is traditional in many IC and there are domestic manufacturers. In this manner, there is availability of spare parts and qualified personnel to perform the services.

However, power generation from fossil fuels is not part of the local economy. In addition to using fuel from distant sources, it generates few jobs, which require relatively high professional qualification. Finally, there is a pronounced environmental impact: a diesel engine releases about $220 \mathrm{kgC} / \mathrm{MWh}$ in the atmosphere, not to mention the potential damage from mishandling of the lubricating oil [15].

As for the efficiency of the diesel generator, the specific consumption of a regularly maintained set is $350 \mathrm{~g} / \mathrm{kWh}$, which results in a thermal efficiency of $24 \%$; for those sets poorly maintained, the specific 


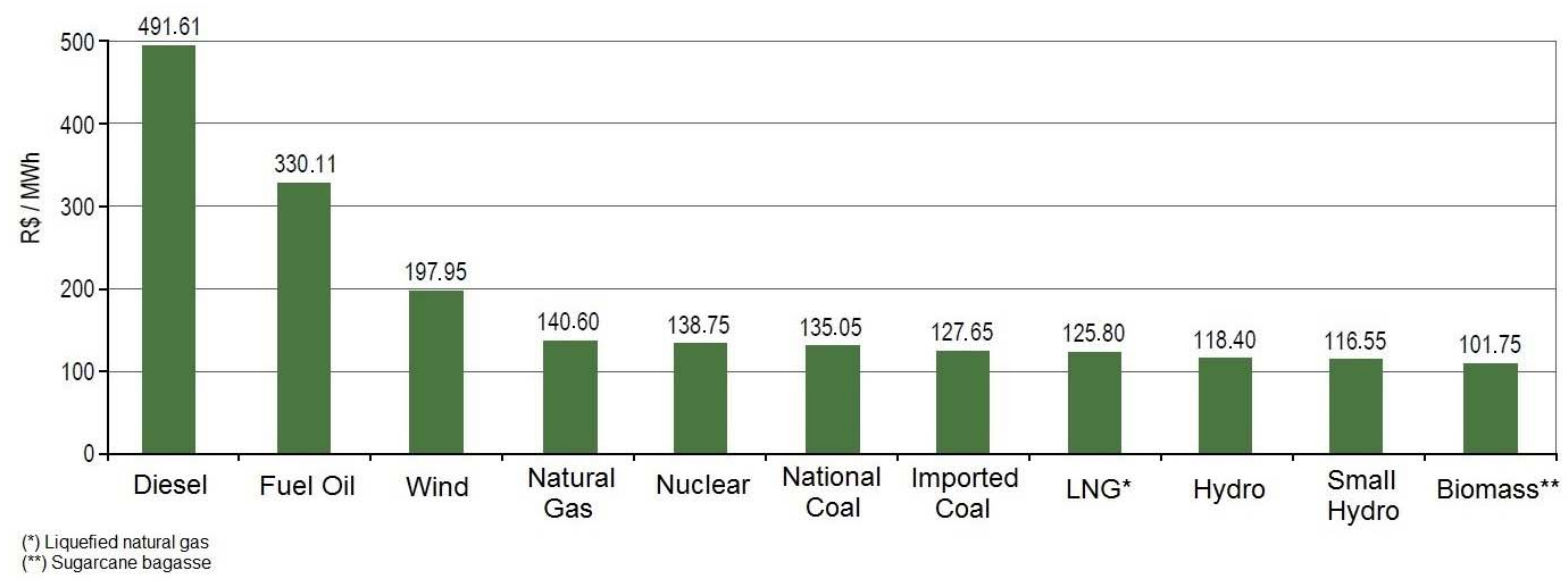

Fig. 2 Production cost of electricity in Brazil, by fuel.

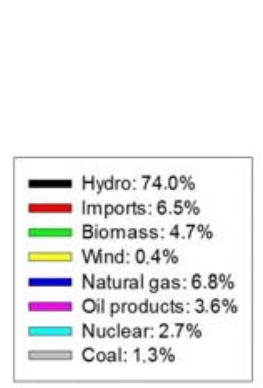

Source: Mme, 2011

\section{Brazil}

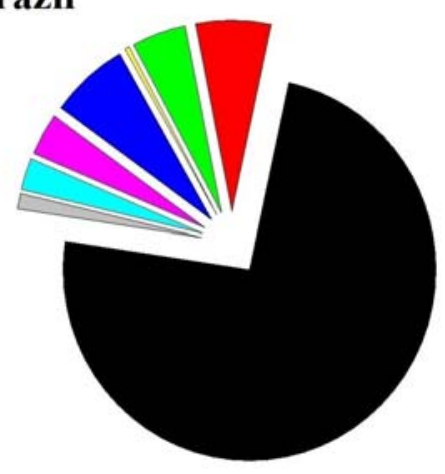

\section{World}

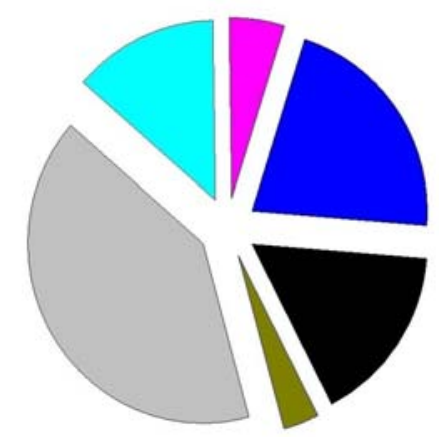

Fig. 3 Electricity generation, by fuel.

consumption increases to $500 \mathrm{~g} / \mathrm{kWh}$, decreasing its efficiency to $17 \%$. Thinking only in terms of energy efficiency, a good replacement for engines operating on diesel fuel must exhibit efficiency greater than $25 \%$.

The use of renewable energy sources implies higher acquisition costs than typical diesel generator sets, and the technology is usually more complex. Therefore, a more efficient approach would make the application

more feasible. As for the conversion technologies available today, Tuckenburg [16] highlights the following: gasification, anaerobic digestion, transesterification and direct combustion. To analyze each of these technologies, it is necessary to take the electric power generation using diesel fuel as standard, and process the comparison of other technologies against it. This assessment is intended to establish a method that would cope with diesel generation, which is undeniably the best technical solution, but neither economically nor environmentally tenable.

\subsection{Gasification}

Small gasifiers have not presented satisfactory results for power generation. Firstly, there is a significant production of tar during firing [17], which can not be totally eliminated in the cleaning of gases, thereby contaminating the generator set, requiring frequent and costly maintenance. The power and efficiency of the engine during operation with biomass gas are lower compared to the use fossil fuels. In the case of a diesel, generator set with electric power of 15 $\mathrm{kW}$ and $22 \%$ efficiency, when the mixture is changed to $20 \%$ diesel and $80 \%$ of gasifier gas, power dropped to $12 \mathrm{~kW}$ and efficiency to $15 \%$. Therefore, in terms of energy efficiency, gasification is not a good alternative to the engine operating on diesel, also demanding biomass of excellent quality for better results. It follows that it is a complex process for use in the IC, 
requiring significant equipment and technical handling.

\subsection{Anaerobic Digestion}

To generate electricity, gases produced by anaerobic digesters must be sent to explosion engines, where there will be some restrictions. In Otto cycle engines, where combustion starts by a spark, the digester gas alone is sufficient to cause combustion and operate the system, but because of its lower calorific value, the engine power is about $50 \%$ lower than rated. In the case of diesel engines, the restriction of power is similar, and for starting the combustion process, continued participation of $20 \%-30 \%$ of diesel oil is necessary. Therefore, the dependence on diesel fuel remains, although in smaller quantities.

\subsection{Transesterification}

Although the production of biodiesel is consolidated, its development in remote and isolated areas is a new option that has yet to be widely tested. The service life of the motors depends on the quality of biodiesel used. Since this is a complex transformation, many procedures have to be performed by plant operators to maintain product quality. It should be stated also that the transesterification process is not simple, requiring strict control of the operation and handling of potentially harmful substances. It is therefore necessary to install massive, accurate and reliable equipment and well qualified staff, whose costs can only be compensated by a minimum production demand. Moreover, attention should be paid to the safety of this type of installation, a widely referred aspect in the legislation, which must be strictly observed.

\subsection{Direct Combustion}

The choice of biomass as a primary energy source can mean a great choice, even considering the high initial cost. Besides being a renewable energy source, this alternative has the advantage of activating IC's economy by generating jobs as a result of the use of native or cultivated combustion material. In fact, this convenience results in the relative simplicity of operation and maintenance, which is added to the economic viability of this system of power generation. In addition, they reduce the environmental liability because of the high losses of third-party sawing and wood processing.

It will be present a proposal that aims to balance the disadvantages previously exhibited by facilities with boiler and steam turbine: working with higher pressure and temperature in the boiler and broadening the power restriction on the plant. Thus, power in the range of tens of kilowatts may be provided while maintaining comparable efficiency, if not higher, compared to those operating on diesel generators.

\section{Conclusions}

From the foregoing, it becomes clear that the option of direct combustion of biomass as a primary energy source can be a good alternative, even considering the high initial cost. On the other hand, systems of electricity generation with boiler and steam turbine are suitable for power above $200 \mathrm{~kW}$. For lower power, steam turbine efficiency is very low, which hinders the application. A question remains: would there not be another machine, not a steam turbine, which provided sufficient power, presented adequate efficiency and, next to a boiler, would allow the burning of biomass? The key to this issue is to utilize a combustion mechanism which can be operated with high pressures and temperatures in the boiler.

In the past, steam engines, for automotive use and special locomotives (known in Brazil as “locomóvel”), used to operate with pressure values around 1.5 $\mathrm{MPa}$ and temperatures of $300{ }^{\circ} \mathrm{C}$, which resulted in efficiencies lower than 10\%. Nodari [18] cites a locomóvel of $216 \mathrm{~kW}$ with only 7.4\% efficiency. The old steam engines, with this level of efficiency, can not compete with modern diesel engines.

The work of Prasad [3] is a good reference on the subject of high pressure, describing the use of a 
three-cylinder steam engine whose exhaust and intake valves are operated by the piston, with working pressure of $6 \mathrm{MPa}$ and $400{ }^{\circ} \mathrm{C}$ temperature in the boiler, reaching these conditions with $17 \%$ efficiency to produce $32 \mathrm{~kW}$. This represents more than double the efficiency of old steam engines-locomóveis. It is noteworthy that a monotube boiler is used, with an average efficiency of $70 \%$, burning biomass (sawdust).

Thinking about improving the technology, an engine operated by steam, with settings totally different from conventional steam engines, is being studied in the Department of Mechanical Engineering at the UFJF (Federal University of Juiz de Fora), aiming to use steam pressure of $8 \mathrm{MPa}$ and a temperature around $500{ }^{\circ} \mathrm{C}$. The expectation is that this engine can be obtained from changes in existing diesel engines in the IC, keeping the power at the same magnitude as the original engine. The boiler should be similar to that used by Ref. [3]. With this engine, its efficiency is predicted to be above $20 \%$, and the study of optimum thermodynamic cycle associated with the engine returns efficiency values of about 35\%. The ideal Rankine cycle, operating under the same conditions of $8 \mathrm{MPa}$ and $500{ }^{\circ} \mathrm{C}$, suggests efficiency around $29 \%$. The manufacturing and operational characteristics of the engine under study in UFJF can not be disclosed at this time, since the filing of a patent for this engine is under way.

Finally, it is possible to state that an efficient technology for generating electricity for the IC, which has great potential to replace diesel generator sets, is the direct combustion of biomass in boilers to produce steam at pressures as high as $6 \mathrm{MPa}$ and temperatures around $500{ }^{\circ} \mathrm{C}$. It is a breakthrough in the operation technique of steam engines and the Mechanical Engineering department in UFJF has sought results accordingly.

\section{References}

[1] W.A. Gonzalez, Biodiesel and Vegetable Oil in Natura:
Energy Solutions for the Amazon, Ministry of Mines and Energy, Brasília, Brazil, 2008.

[2] Eletrobrás, Sustainability report, Rio de Janeiro, Brazil, 2011.

[3] S.B. Prasad, Biomass-fired steam power cogeneration system: A theoretical study, Energy Conversion and Management 36 (1) (1995) 65-77..

[4] Amazonas, State Government, Emissions Inventory of Greenhouse Gases from Electric Sector of the State of Amazonas, Secretary of State for Environment and Sustainable Development, Manaus, Brazil, 2010.

[5] ANEEL-National Electric Energy Agency, Atlas of Electric Power in Brazil, 3rd ed., Brasília, Brazil, 2008.

[6] Eletrobrás, Riparian Project: Technological Alternatives, 2007.

[7] L.T.R. Rosário, R.V. Els, A.C.P.J. Júnior, Alternative Energy for Isolated Communities in the Amazon: The Hydrokinetic Energy in Maraca, Southern Amapá, 2005.

[8] Sources of Biomass, BEC-Biomass Energy Centre, Farnham, England, 2012.

[9] Mme-Ministry of Mines and Energy, National Energy Balance 2011: Base year 2010, EPE, Rio de Janeiro, Brazil, 2011.

[10] Key World Energy Statistics, IEA-International Energy Agency, Paris, France, 2011.

[11] J.M.C. Lobo, Assessment of the Energy Potential of Waste Biomass Amazon, Itajubá, Brazil, 2002.

[12] A.C. Hummel, Rules on Access to the Forest Resource in the Brazilian Amazon: The Case of Forest Management, Manaus, Brazil, 2001.

[13] J. Werther, M. Saenger, E. Hartge, T. Ogada, Z. Siagi, Combustion of agricultural residues, Progress in Energy and Combustion Science 26 (1) (2000) 1-27.

[14] M.A. Di Lascio, Energy and Sustainable Development for the Rural Brazilian Amazonia: Electrification of Isolated Communities, Ministry of Mines and Energy, Brasilia, Brazil, 2009.

[15] G. Rendeiro, Combustion and Gasification of Solid Biomass: Energy Solutions for the Amazon, Ministry of Mines and Energy, Brasilia, Brazil, 2008.

[16] W.C. Tuckenburg, Renewable Energy Technologies, World Energy Assessment of the United Nations, UNDP, UNDESA/WEC, 2000.

[17] O.T. Kinto, Energy from Biomass Gasification, an Unconventional Resource for Clean Development, Barueri, Brazil, 2003.

[18] I.L. Nodari, State of the art and perspectives in thermoelectric generation via biomass in the state of Rio Grande do Sul, Mater's thesis, PROMEC/UFRGS, Porto Alegre, Brazil, 1996. 